\title{
Influência do manejo do rebanho, das condições higiênicas da ordenha e da fase de lactação na composição química do leite de cabras Saanen
}

\author{
Rita de Cássia Ramos do Egypto Queiroga1, Roberto Germano Costa2, Telma Maria Barreto \\ Biscontini $^{3}$, Ariosvaldo Nunes de Medeiros ${ }^{4}$, Marta Suely Madruga ${ }^{5}$, Alexandre Ricardo \\ Pereira Schuler6
}

\footnotetext{
1 Departamento de Nutrição/CCS/UFPB, CEP: 58059-900, João Pessoa-PB.

2 Departamento de Agropecuária/CFT/UFPB, CEP: 58220-000, Bananeiras-PB.

3 Departamento de Nutrição/CCS/UFPE, CEP: 50670-901, Recife-PE.

${ }^{4}$ Departamento de Zootecnia/CCA/UFPB, CEP: 58397-000, Areia-PB.

${ }^{5}$ Departamento de Tecnologia e Química de Alimentos/CT/UFPB, CEP: 58059-900, João Pessoa-PB.

${ }^{6}$ Departamento de Engenharia Química/UFPE, CEP: 50670-901, Recife-PE.
}

RESUMO - Objetivou-se avaliar a influência dos períodos de lactação nas características químicas e físicas do leite de cabras Saanen no Brejo Paraibano, Brasil, e verificar o efeito do manejo do rebanho, da higiene da ordenha e dos períodos da lactação no perfil lipídico do leite. Vinte animais foram selecionados, constituindo-se quatro grupos de 5 (com e sem a presença do macho e ordenha com e sem procedimentos de higiene) para análises de amostras de leite coletadas com 35, 85 e 135 dias de lactação. Os resultados comprovaram produtividade leiteira satisfatória em 135 dias de lactação, evidenciando produção máxima aos 35 dias e comportamento linear decrescente com o avanço da lactação. Os teores de lipídios e acidez variaram no decorrer da lactação. A higiene da ordenha e o manejo do rebanho não tiveram efeito sobre o perfil de ácidos graxos, no entanto, os valores médios de ácidos graxos saturados foram influenciados pela fase de lactação, observando-se os maiores percentuais de ácidos graxos de cadeia curta aos 85 dias da lactação. Os teores médios de ácidos graxos insaturados também foram modificados por este fator e apresentaram os maiores valores aos 35 dias de lactação.

Palavras-chave: ácidos graxos, caprinos leiteiros, constituintes do leite

\section{Effects of flock management, milking sanitary conditions and lactation stage on milk composition of Saanen goats}

\begin{abstract}
The objective of this trial was to evaluate the effect of lactation stage in the chemical and physical characteristics of milk from Saanen goats as well as to investigate the effects of flock management, milking sanitary conditions, and lactation phase in the milk fatty acid profile. Twenty goats were randomly assigned to four groups of five animals each. Flock management differed by the presence or absence of males in the groups while milking sanitary conditions differed either by a poor or by a good milking hygiene. Milk samples were collected at 35, 85 and 135 days of lactation. Results showed that milk yield was as expected at 135 days of lactation; peak milk production was observed at 35 days of lactation and decreased linearly as lactation progressed. Milk yield, milk fat content, and milk acidity all changed according to the lactation stage. Milking sanitary conditions and flock management did not affect the milk fatty acids profile. However, milk fatty acids profile differed at different lactation stages with the greatest content of saturated fatty acids at 85 days of lactation.
\end{abstract}

Key Words: dairy goat, fatty acid, milk constituents

\section{Introdução}

A produtividade leiteira caprina brasileira, apesar do rebanho numericamente representativo, ainda possui índices reduzidos de desempenho (128.000 Mt/ano), sobretudo quando confrontada à de países europeus, como França e Espanha, que produzem anualmente 525 e 350 mil toneladas, respectivamente (FAOSTAT, 2003). A precariedade da tecnologia usualmente aplicada no Brasil e a ausência de padrões de controle higiênico-sanitário do leite de cabra e de seus derivados têm-se constituído os principais entraves à agroindústria especializada em produtos lácteos de caprinos, estando a expansão deste setor vinculada à melhoria da estrutura de comercialização e à aplicação de tecnologia adequada aos padrões de qualidade exigidos (Simplicio \& Wander, 2003).

A importância do leite de cabra na alimentação se deve ao seu alto valor nutritivo, à maior digestibilidade e às 
suas características terapêuticas e dietéticas (Haenlein, 2004; McCullough, 2004; Moneret-Vautrin, 2004). Pesquisas têm sido direcionadas à sua composição, contudo, pouco se sabe sobre a composição nas regiões semi-áridas e nas microrregiões do Brasil, principalmente quanto ao efeito de fatores como raça, mestiçagem, ambiente e período de lactação na qualidade do leite produzido.

A fase de lactação representa importante fator de variação nas características de composição do leite. Pesquisas indicam que os valores de proteína, lipídios e lactose aumentam no decorrer da lactação (Aganga et al., 2002; Prasad \& Sengar, 2002).

O conhecimento do perfil lipídico dos alimentos é importante para a nutrição humana, com relevante atenção no aparecimento de patologias cardiovasculares. A fração gordurosa do leite é influenciada por diferentes tipos de manejos. Segundo Jaubert et al. (1997), as características químicas e sensoriais do leite caprino, especialmente a intensidade do sabor, diferem conforme a fase da lactação e o maior conteúdo de gordura. Segundo Haenlein (2004), a quantidade de ácidos graxos de cadeia curta (caprílico C6:0, capróico - C8:0 e cáprico - C10:0) no leite caprino é quase três vezes maior que a do leite de vaca, tornando-os química e fisiologicamente distintos. Soryal et al. (2004) observaram incremento de ácidos graxos de cadeias curta e longa com o avanço da lactação em amostras de leite de cabra Alpinas.

Chilliard et al. (2001) e Schmidely \& Sauvant (2001) afirmaram que, com o metabolismo energético e com o fornecimento de precursores à glândula mamária, fatores relacionados ao rúmen afetam o volume de produção, a quantidade e a qualidade da gordura produzida no leite do animal. $\mathrm{O}$ aporte em quantidade e qualidade de gordura na dieta tem efeito direto sobre a fermentação ruminal, provocando alterações na flora celulolítica.

A qualidade microbiológica do leite está relacionada às condições higiênico-sanitárias da obtenção, com influência direta na qualidade do produto final. Os processos lipolítico, provocados por ação bacteriana ocasionam a degradação dos ácidos graxos e formação de voláteis com conseqüente efeito nas características sensoriais do leite (DelacroixBuchet \& Lamberet 2000; Gonzalo, 2004).

Os criadores de caprinos leiteiros utilizam usualmente a prática do manejo do rebanho com o isolamento do animal macho, retirando-o da companhia das fêmeas. Entretanto, dados científicos são escassos sobre a influência deste procedimento nas características sensoriais do leite caprino, sendo necessárias investigações que forneçam aos produtores informações sobre as práticas adequadas de produção e beneficiamento.
Objetivou-se com esta pesquisa determinar, durante os períodos de lactação, a produção e a composição química do leite de cabras Saanen e avaliar o perfil de ácidos graxos do leite desses animais submetidos a diferentes manejos do rebanho e condições de higiene de ordenha.

\section{Material e Métodos}

O experimento foi realizado no Setor de Caprinocultura do Departamento de Agropecuária da Universidade Federal da Paraíba, Campus de Bananeiras, Microrregião do Brejo Paraibano. As análises físico-químicas e o perfil de ácidos graxos foram determinados no Laboratório Experimental de Análises de Alimentos (LEAAL) da Universidade Federal de Pernambuco.

Foram utilizadas 20 cabras Saanen, selecionadas segundo a data e o número de parições, elegendo-se as de 2 a e 3 a cria com mesma época de parição. A produção e a composição química do leite dos animais foram avaliadas em três períodos, com coletas aos 35, 85 e 135 dias da lactação, respectivamente. As ordenhas foram realizadas manualmente às 6 e $16 \mathrm{~h}$.

Os animais utilizados neste trabalho foram criados em sistema intensivo e receberam ração completa com $14 \%$ de $\mathrm{PB}$ e 2,16 Mcal de EM/kg MS, composta de 50\% de volumoso (capim-tifton) e $50 \%$ de concentrado comercial (milho, soja e trigo), suplemento mineral e água à vontade. A dieta foi calculada para atender às exigências nutricionais de cabras em lactação com produção média de $2 \mathrm{~kg} / \mathrm{dia}$.

Os animais selecionados foram distribuídos em dois grupos experimentais (dez em cada grupo) e submetidos a diferentes estratégias de manejo. O primeiro grupo foi mantido sem o reprodutor e o segundo com a presença do reprodutor. Para análise da condição higiênico-sanitária de ordenha, subdividiu-se cada grupo de dez animais em dois subgrupos de cinco animais: no primeiro, não se procedeu a nenhuma higiene na ordenha, enquanto, no segundo, aplicaram-se os seguintes cuidados higiênicos: a) lavagem dos tetos com água corrente e secagem com papel toalha; b) eliminação dos primeiros jatos de leite; c) desinfecção dos tetos com solução glicerinoiodada (Egito, 1991).

Em todas as coletas, os utensílios foram previamente lavados com água e sabão neutro e secos à temperatura ambiente. O leite ordenhado dos grupos foi homogeneizado com bastão de vidro e pesado, sendo retiradas amostras de $250 \mathrm{~mL}$, as quais foram acondicionadas em recipientes e transportadas ao laboratório em caixa de isopor com gelo para análises da composição química. Amostras individua is de $250 \mathrm{~mL}$ foram coletadas para análise do perfil dos ácidos graxos. 
Para determinação do potencial leiteiro, manteve-se a rotina do setor: o leite de cada ordenha individual era colocado em balde previamente tarado, sendo imediatamente pesado. $O$ procedimento era realizado semanalmente, para cada animal em separado, durante os períodos experimentais. As somas dos pesos das ordenhas matutinas e vespertinas corresponderam à produção média diária por grupo de animais.

No leite, foram determinados o teor de $\mathrm{PB}$ pelo método Micro-Kjedahl (métodos AOAC, 991.20 e 991.23); o extrato seco total por secagem até obtenção de peso constante (método AOAC, 925.23) (AOAC, 1998); o teor de lipídio utilizando-se o lacto-butirômetro de Gerber; a lactose pela redução de Fehling, em que os resultados são expressos em lactose $(\mathrm{g} / 100 \mathrm{~g})$; a densidade, por leitura em termolactodensímetro a $15^{\circ} \mathrm{C}$ (Instituto Adolfo Lutz, 1985); e a acidez, expressa em ${ }^{\circ} \mathrm{D}$ (método AOAC 947.05) (AOAC, 1998).

Para identificação do perfil de ácidos graxos, amostras de $100 \mathrm{~mL}$ de leite de cada um dos animais dos grupos experimentais foram submetidas à centrifugação a frio, para separação da gordura dos demais nutrientes. Destas amostras, retiraram-se alíquotas de $2 \mathrm{~g}$ para os processos de extração (Folch et al., 1957), saponificação e esterificação. Após a extração, foi realizada a metilação conforme descrito por Hartman \& Lago (1973). Os ésteres produzidos foram analisados em cromatógrafo a gás modelo CG Máster, com detector de ionização de chama, coluna capilar (Carbowax 20M). O programa de temperatura do forno inicial foi o de $70^{\circ} \mathrm{C}$, com graduação de $6^{\circ} \mathrm{C} / \mathrm{min}$ até $145^{\circ} \mathrm{C}$ na $1^{\mathrm{a}}$ rampa, mudando para $2^{\circ} \mathrm{C} / \mathrm{min}$ até à temperatura final de $190^{\circ} \mathrm{C}$. Os dados sobre os tempos de retenção e as percentagens dos ácidos graxos foram obtidos por intermédio do software - Peaksimple (SRI Instruments USA). Os resultados dos ácidos graxos foram expressos em percentual de área $(\%)$.

Os dados das características químicas, físicas e de produção foram submetidos à análise de variância com regressão, em um delineamento inteiramente casualizado, com três tempos de lactação, e à análise de correlação de Pearson, cuja significância dos coeficientes (r) foi determinada pelo teste $\mathrm{t}$ de Student a 5 e $1 \%$ de probabilidade.

$\mathrm{Na}$ análise do perfil de ácidos graxos, utilizou-se u m delineamento com arranjo fatorial $2 \times 2 \times 3$, envolv endo os fatores manejo do rebanho, higiene da ordenha e períodos da lactação. A comparação entre médias foi feita pelo teste Tukey a $5 \%$ de probabilidade (SAS, 1996)

\section{Resultados e Discussão}

Os resultados da produtividade leiteira foram expressos em média de produção diária (Figura 1). As médias obtidas aos 35, 85 e 135 dias de lactação foram 1.645, 1.460 e 1.165 g/dia, respectivamente. De acordo com a regressão linear, a produção de leite diminuiu à medida que aumentou o tempo de lactação, com decréscimo de 4,710 g/dia de lactação.

Os valores de produção determinados neste estudo foram superiores aos citados por Faria (1987), Queiroga (1995) e Tholon (2000), com valores diários de 1,02; 0,89 e $0,77 \mathrm{~kg}$, respectivamente, e provavelmente foram ocasionados pela curta duração do período de lactação (135 dias), entretanto, foram inferiores aos obtidos por esses autores aos 356, 195 e 288 dias de lactação, respectivamente. O período de lactação experimental foi estabelecido em 135 dias porque algumas cabras apresentavam-se prenhes, pela presença do reprodutor. Para não haver comprometimento dos resultados produtivos dos grupos, 135 dias de lactação como foi considerado o período final, visto que a gestação ocasionou diminuição na produção de leite desses animais.

As médias de produção registradas foram superiores à do estado da Paraíba, de 0,70 L/dia (Souza Neto \& Guttierrez, 1987). Ressalta-se, no entanto, que os animais utilizados eram da raça Saanen (raça exótica, originária do Vale de Saanen, Suíça, com aptidão leiteira) e se mostraram bem adaptados às condições brasileiras (Tholon, 2000).

Os valores médios das características químicas e físicas do leite de cabras Saanen nas diferentes fases de lactação estão expressos na Tabela 1. Verificou-se também que os teores de gordura e acidez diferiram nos períodos de lactação ( $\mathrm{P}<0,05)$, aumentando aos 135 dias de lactação, com valores de $3,9 \mathrm{~g} / 100 \mathrm{~g}$ para gordura e $16,5^{\circ} \mathrm{D}$ para acidez.

Fatores como raça, condições do clima, período de lactação e disponibilidade de alimentos podem afetar a composição, as características físico-químicas e a produção de leite (Aganga et al, 2002; Soryal et al., 2003). De acordo com Jenness (1980), entre os principais fatores que afetam o teor de proteína do leite de cabra, destacam-se a raça e o período de lactação, seguidos da variação sazonal. Neste sentido, Rota et al. (1993) afirmaram que a tendência dos teores de proteína e gordura segue uma evolução inversa à da produção de leite, alcançando valores mínimos no segundo mês de lactação, que coincidem com a produção máxima de leite. Os dados da literatura são controversos quanto ao percentual de proteína em relação ao período de lactação. Alguns autores afirmam que o conteúdo de proteína decresce no decorrer da lactação (Faria, 1987; 


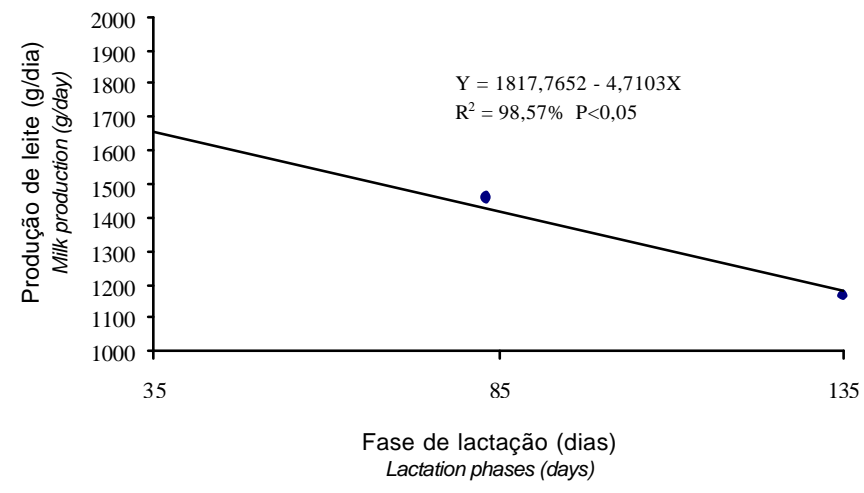

Figura 1 - Produção de leite (g/dia) de cabras Saanen em três fases da lactação.

Figure 1 - Milk production (g/day) of Saanen gotas at 35, 85, and 135 days of lactation.

Voutsinas et al., 1990), enquanto outros afirmam o contrário (Veinoglou et al., 1982).

Faria (1987) observou que os teores de proteína tenderam a diminuir até aproximadamente 120 dias de lactação, no entanto, não verificou variações significativas nos seus valores com aumento do aporte de proteína (50\%), ministrado sob a forma de concentrado protéico. Esses resultados estão de acordo com os apresentados por Fehr \& Sauvant (1980) e Goetsch et al (2001), que afirmaram que a porcentagem protéica permanece constante mesmo quando aumenta a quantidade de proteína na ração dos animais. Os resultados médios de proteína obtidos nesta pesquisa não apresentaram variações $(\mathrm{P}>0,05)$.

O teor de gordura do leite caprino é susceptível a oscilações provocadas por fatores como raça, turno de ordenha e período de lactação. Algumas raças se caracterizam pela baixa produção de leite com alto teor de gordura, como a raça Anglo-Nubiana, ou pela elevada quantidade de leite com baixo teor de gordura, como a raça Saanen. Outros fatores, como a disponibilidade de determinados alimentos, e a sazonalidade, também interferem na quantidade de gordura do leite de cabra.

Os valores médios para a porcentagem de lipídio encontrados neste experimento foram inferiores aos obtidos por diversos autores, como Karim \& Lofti (1987), no Irã, que avaliaram o leite de cabras mestiças Saanen e Nadji e encontraram 3,7\% de lipídios. Barbosa \& Miranda (1986), analisando amostras de leite de cabras Saanen provenientes de seis áreas geográficas distintas de Portugal, encontraram valor médio de 3,6\% de lipídios e Queiroga (1995), no Brejo Paraibano (Brasil), registrou teor médio de 4,6\% de lipídios em amostras de leite de animais mestiços Saanen. Do mesmo modo, Silva (2001) registrou no leite de cabras Saanen em
Pernambuco (Brasil), valor médio de 3,9\% de gordura, similar ao reportado (3,8\%) por Chornobai et al. (1999).

Goetsch et al. (2001), estudando o efeito da dieta na produção e composição do leite de cabras Alpinas, observaram que a dieta influencia os teores de gordura do leite, sobretudo em animais de parição tardia, verificando-se relação direta com a ingestão e o metabolismo energético. Esses autores ressaltaram que a dieta está diretamente associada às condições hormonais, como o efeito da insulina sobre os níveis de absorção de glicose e propionato, que podem modificar o estado sangüíneo e a síntese de gorduras.

$\mathrm{O}$ valor médio de lactose determinado $(4,1 \mathrm{~g} / 100 \mathrm{~g})$ foi semelhante aos reportados por Anifantakis \& Kandarakis (1980), Queiroga (1995), Prata et al. (1998) e Sung et al. (1999), que obtiveram valores de 4,3;4,2; 4,3 e 4,6\%, respectivamente. A lactose é um dos nutrientes mais estáveis na composição química do leite e está diretamente relacionada à regulação da pressão osmótica, de modo que maior produção de lactose determina maior produção de leite com mesmo teor de lactose. Entretanto, Goetsch et al. (2001) verificaram que o teor de lactose foi influenciado pelos diferentes níveis de concentrado da dieta, apresentando diferenças ao longo da lactação em animais com parição tardia, o que não foi observado nos animais com parição precoce.

Quanto ao teor de extrato seco total (11,4 g/100 g), o valor determinado foi inferior aos registrados por Karim \& Lofti (1987), Barbosa \& Miranda (1986), Queiroga (1995), Prata et al. (1998) e Chornobai et al. (1999), de 12,3; 12,$1 ; 12,7 ; 12,4$ e $12,2 \%$, respectivamente. Entretanto, Sung et al. (1999) e Morgan et al. (2003) citaram valores aproximados $(11,1$ e $11,8 \%)$.

Os valores de acidez detectados estão de acordo com os limites preconizados pela legislação vigente e, portanto, as variações observadas podem estar relacionadas a diferenças no teor dos ácidos carboxílicos e no perfil microbiológico do leite.

Na Tabela 2, são representados os valores referentes aos coeficientes de correlação entre os parâmetros químicos, físicos e de produção das amostras de leite de cabras Saanen. Correlacionando os valores de proteína aos de gordura, observou-se forte correlação $(r=0,855)$, com significativas interações acidez $\times$ gordura $(r=0,852) \mathrm{e}$ acidez $\times$ lactose $(r=0,731)$. A interação acidez $\times$ gordura provavelmente está relacionada às variações dos grupos carboxílicos presentes ao leite, enquanto a interação acidez $\times$ lactose pode ser atribuída à tendência de a disponibilidade da lactose desdobrar-se em ácido lático por ação microbiana, o que acarreta aumento da acidez e diminuição 
Tabela 1 - Características físicas e químicas do leite de cabras Saanen em diferentes fases da lactação Table 1 - Chemical and physical characteristics of milk from Saanen goats in different stages of lactation

\begin{tabular}{|c|c|c|c|c|c|c|c|}
\hline $\begin{array}{l}\text { Fase (dias) } \\
\text { Phase (days) }\end{array}$ & $\begin{array}{c}\text { Proteína } \\
(\mathrm{g} / 100 \mathrm{~g}) \\
\text { Protein }\end{array}$ & $\begin{array}{c}\text { Lipídios } \\
(\mathrm{g} / 100 \mathrm{~g}) \\
\text { Fat }\end{array}$ & $\begin{array}{c}\text { Lactose } \\
(\mathrm{g} / 100 \mathrm{~g}) \\
\text { Lactose }\end{array}$ & $\begin{array}{c}\mathrm{EST}^{1} \\
(\mathrm{~g} / 100 \mathrm{~g}) \\
D T E\end{array}$ & $\begin{array}{c}\mathrm{SNG}^{2} \\
(\mathrm{~g} / 100 \mathrm{~g}) \\
\text { SNF }\end{array}$ & $\begin{array}{c}\text { Densidade } \\
\left(\mathrm{g} / \mathrm{cm}^{3}\right) \\
\text { Density }\end{array}$ & $\begin{array}{l}\text { Acidez } \\
\left({ }^{\circ} \mathrm{D}\right) \\
\text { Acidity }\end{array}$ \\
\hline 35 & $2,7 \pm 0,09^{a}$ & $3,3 \pm 0,32^{a b}$ & $4,2 \pm 0,24^{\mathrm{a}}$ & $11,7 \pm 0,45^{\mathrm{a}}$ & $8,39 \pm 0,25^{\mathrm{a}}$ & $1032,2 \pm 0,87^{\mathrm{a}}$ & $15,0 \pm 0,00^{\mathrm{b}}$ \\
\hline 85 & $2,6 \pm 0,09^{\mathrm{a}}$ & $2,9 \pm 0,05^{\mathrm{b}}$ & $4,2 \pm 0,41^{\mathrm{a}}$ & $10,8 \pm 0,07^{\mathrm{a}}$ & $7,85 \pm 0,06^{\mathrm{a}}$ & $1031,7 \pm 0,90^{\mathrm{a}}$ & $14,2 \pm 0,50^{\mathrm{b}}$ \\
\hline 135 & $2,8 \pm 0,28^{\mathrm{a}}$ & $3,9 \pm 0,57^{\mathrm{a}}$ & $3,9 \pm 0,25^{\mathrm{a}}$ & $11,7 \pm 0,78^{\mathrm{a}}$ & $7,74 \pm 0,08^{a}$ & $1031,2 \pm 0,86^{\mathrm{a}}$ & $16,5 \pm 0,58^{a}$ \\
\hline Média & $2,7 \pm 0,20$ & $3,4 \pm 0,54$ & $4,1 \pm 0,37$ & $11,4 \pm 0,63$ & $7,99 \pm 0,28$ & $1031,7 \pm 0,89$ & $15,2 \pm 1,06$ \\
\hline \multicolumn{8}{|l|}{ Mean } \\
\hline $\mathrm{Dms}$ & 0,35 & 0,75 & 0,61 & 1,03 & 1,03 & 1,73 & 0,87 \\
\hline$L S D$ & & & & & & & \\
\hline
\end{tabular}

1 Extrato seco total (Dry total extract).

2 Sólidos não gordurosos (Solids non-fat).

Nas colunas, médias seguidas da mesma letra não diferem ( $P>0,05)$ pelo teste Tukey(Means followed by the same letter in the column did not differ [P>0.05] by Tukey test).

Tabela 2 - Coeficientes de correlação de Pearson ( $r$ para as características físicas e químicas e produção do leite de cabras Saanen Table 2 - Pearson correlation coefficients ( $r$ ) between physical and chemical characteristics of milk and milk production of Saanen goats

\begin{tabular}{|c|c|c|c|c|c|c|c|}
\hline & $\begin{array}{c}\text { Gordura } \\
\text { Fatty } \\
\end{array}$ & $\begin{array}{l}\text { Lactose } \\
\text { Lactose }\end{array}$ & $\begin{array}{c}\mathrm{EST}^{1} \\
S D T\end{array}$ & $\begin{array}{c}\mathrm{SNG}^{2} \\
S N G\end{array}$ & $\begin{array}{c}\text { Densidade } \\
\text { Density }\end{array}$ & $\begin{array}{l}\text { Acidez } \\
\text { Acidity }\end{array}$ & $\begin{array}{c}\text { Produção de leite } \\
\text { Milkproduction }\end{array}$ \\
\hline Proteína (Protein) & $+0,855 * *$ & $-0,581^{*}$ & $+0,311$ & $-0,472$ & $-0,105$ & $+0,672 *$ & $-0,533$ \\
\hline Gordura (Fat) & & $-0,608 *$ & $+0,565$ & $-0,322$ & $-0,248$ & $+0,852 * *$ & $-0,606 *$ \\
\hline Lactose (Lactose) & & & $-0,274$ & $+0,204$ & $+0,205$ & $-0,731 * *$ & $0,705^{*}$ \\
\hline $\operatorname{EST}(D T E)$ & & & & $+0,599 * *$ & $+0,184$ & $+0,581 *$ & $-0,217$ \\
\hline $\mathrm{SNG}(S N F)$ & & & & & $+0,452$ & $-0,159$ & $+0,338$ \\
\hline Densidade (Density) & & & & & & $-0,190$ & $+0,233$ \\
\hline Acidez (Acidity) & & & & & & & $-0,667 *$ \\
\hline
\end{tabular}

1 Extrato seco total (Dry total extract).

2 Sólidos não gordurosos (Solids non-fat).

${ }^{*} \mathrm{e}^{* *}$ Significativo a 5 e $1 \%$ de probabilidade, respectivamente, pelo teste $\mathrm{t}$ de Student ( ${ }^{*}$ and ${ }^{* *}$ Significant at 5 and $1 \%$ of probability, respectively, by Student $t$ test).

do teor de lactose. Nader Filhoet al. (1990) observaram, em amostras de leite caprino, que o teor de acidez aumentou com o avanço da lactação. O mesmo foi observado neste estudo, com variações $(\mathrm{P}<0,05)$ durante os períodos analisados. A interação gordura $\times$ produção de leite no estudo realizado por esse autor foi negativa $(r=-0,606)$, o que está de acordo com o obtido nesta pesquisa. Houve, no entanto, correlação para lactose e produção $(r=0,705)$, diferente do observado neste estudo.

De acordo com os limites preconizados pela legislação vigente para o leite de cabra (BRASIL, 2000), os resultados obtidos mantiveram-se abaixo do especificado para os teores de proteína, lactose e sólidos não gordurosos ( $\mathrm{SNG}$ ), de 2,$8 ; 4,3$ e $8,2 \%$, respectivamente, o que evidencia a necessidade de mais pesquisas envolvendo os limites estabelecidos pelas legislações, visto que não representam muitas vezes as características dos leites produzidos pelos rebanhos nacionais.

Os valores obtidos para o perfil de ácidos graxos do leite, expressos em percentual de área (\%), de acordo com os parâmetros estudados, são descritos nas Tabelas 3 e 4 . Foram identificados 22 ácidos graxos, dos quais 15 são saturados, cinco monoinsaturados e dois poliinsaturados.
Dos saturados, destacaram-se o cáprico (C10:0), o mirístico (C14:0), o palmítico (C16:0) e o esteárico (C18:0), todos com valores expressos em área percentual (\%), de 9,35; 8,$65 ; 24,48$ e $12,88 \%$. Entre os monoinsaturados, o ácido oléico apresentou o maior percentual (20,51\%), enquanto, entre os polinsaturados, registrou-se valor de $1,90 \%$ para o ácido linoléico. Foi observada também predominância dos ácidos graxos saturados $(75,91 \%)$, seguidos dos monoinsaturados $(21,89 \%)$.

O fator manejo do rebanho não influenciou $(\mathrm{P}>0,05)$ os percentuais dos ácidos graxos identificados, com exceção do ácido láurico (C12:0), de maior valor $(5,61 \%)$ para o grupo dos animais com presença do macho. Esta variação observada, de forma isolada, pode ser atribuída às características individuais dos animais que compuseram os grupos.

Dentro do fator higiene, os teores não diferiam entre todos os ácidos determinados. Entretanto, na análise do perfil de ácidos graxos nos períodos de lactação, detectaram-se diferenças $(\mathrm{P}<0,05)$ para os ácidos saturados nos compostos identificados, com exceção dos ácidos heptanóico (C7:0), láurico (C12:0), mirístico (C14:0), pentadecanóico (C15:0), palmítico (C16:0) e araquídico (C20:0). Quanto aos ácidos insaturados, todos apresentaram variações $(\mathrm{P}<0,05)$ 
Tabela 3 - Perfil de ácidos graxos saturados do leite de cabras Saanen sob diferentes estratégias de manejo e higiene da ordenha, em três fase da lactação

Table 3 - Effects of flock management, milking sanitary conditions, and lactation stage on the milk profile of saturated fatty acids in Saanen goats

\begin{tabular}{|c|c|c|c|c|c|c|c|c|}
\hline \multirow[t]{2}{*}{$\begin{array}{l}\text { Ácido grax } \\
\text { Fatty acid }\end{array}$} & \multicolumn{2}{|c|}{$\begin{array}{c}\text { Manejo } \\
\text { Flock management }\end{array}$} & \multicolumn{2}{|c|}{$\begin{array}{c}\text { Ordenha } \\
\text { Milking sanitary condition }\end{array}$} & \multicolumn{3}{|c|}{$\begin{array}{c}\text { Fase de lactação (dias) } \\
\text { Lactation stage (days) }\end{array}$} & \multirow[t]{2}{*}{$\begin{array}{l}\text { Média } \\
\text { Mean }\end{array}$} \\
\hline & $\begin{array}{l}\text { Sem macho } \\
\text { Without male }\end{array}$ & $\begin{array}{c}\text { Com macho } \\
\text { With male }\end{array}$ & $\begin{array}{l}\text { Sem higiene } \\
\text { Poor hygiene }\end{array}$ & $\begin{array}{l}\text { Com higiene } \\
\text { Good hygiene }\end{array}$ & 35 & 85 & 135 & \\
\hline C 4:0 & $3,23 \pm 2,42$ & $3,00 \pm 2,17$ & $3,23 \pm 2,21$ & $3,00 \pm 2,37$ & $0,77 \pm 0,24^{\mathrm{c}}$ & $5,81 \pm 1,53^{\mathrm{a}}$ & $3,00 \pm 0,79^{b}$ & $3,12 \pm 2,67$ \\
\hline C 6:0 & $3,83 \pm 2,53$ & $3,46 \pm 2,64$ & $3,20 \pm 2,47$ & $4,09 \pm 2,65$ & $0,79 \pm 0,19^{b}$ & $5,05 \pm 1,27^{\mathrm{a}}$ & $5,09 \pm 2,37^{\mathrm{a}}$ & $3,65 \pm 2,57$ \\
\hline C 7:0 & $0,74 \pm 0,16$ & $0,60 \pm 0,18$ & $0,78 \pm 0,81$ & $0,57 \pm 0,14$ & $0,23 \pm 0,20$ & $0,85 \pm 0,21$ & $0,94 \pm 0,55$ & $0,68 \pm 0,15$ \\
\hline C 8:0 & $4,20 \pm 2,04$ & $3,95 \pm 2,06$ & $4,26 \pm 1,98$ & $3,89 \pm 2,12$ & $2,59 \pm 1,40^{\mathrm{b}}$ & $5,95 \pm 1,72^{a}$ & $3,69 \pm 1,31^{\mathrm{a}}$ & $4,08 \pm 2,02$ \\
\hline C 9:0 & $0,84 \pm 0,55$ & $0,84 \pm 0,57$ & $0,74 \pm 0,67$ & $0,60 \pm 0,17$ & $0,02 \pm 0,01^{\mathrm{b}}$ & $1,22 \pm 0,68^{a}$ & $0,76 \pm 0,49^{\mathrm{a}}$ & $0,67 \pm 0,11$ \\
\hline C 10:0 & $9,75 \pm 1,75$ & $9,04 \pm 1,98$ & $9,43 \pm 1,98$ & $9,36 \pm 1,92$ & $8,59 \pm 1,84^{\mathrm{b}}$ & $10,63 \pm 1,61^{a}$ & $8,96 \pm 1,63^{a b}$ & $9,39 \pm 1,88$ \\
\hline C 11:0 & $1,04 \pm 0,34$ & $1,63 \pm 1,04$ & $1,25 \pm 1,29$ & $1,42 \pm 0,35$ & $0,08 \pm 0,02^{\mathrm{b}}$ & $2,22 \pm 1,33^{\mathrm{a}}$ & $1,70 \pm 0,32^{\mathrm{a}}$ & $1,33 \pm 0,23$ \\
\hline C 12:0 & $4,25 \pm 1,10^{\mathrm{b}}$ & $5,61 \pm 1,16^{\mathrm{a}}$ & $5,64 \pm 2,20$ & $4,22 \pm 1,60$ & $4,78 \pm 2,15$ & $4,73 \pm 1,03$ & $5,29 \pm 2,69$ & $4,93 \pm 2,03$ \\
\hline C 13:0 & $0,92 \pm 0,21$ & $0,93 \pm 0,26$ & $1,03 \pm 0,25$ & $0,88 \pm 0,23$ & $0,07 \pm 0,02^{\mathrm{b}}$ & $0,94 \pm 0,19^{\mathrm{a}}$ & $1,76 \pm 0,37^{\mathrm{a}}$ & $0,92 \pm 0,17$ \\
\hline C $14: 0$ & $8,92 \pm 1,90$ & $8,39 \pm 3,00$ & $8,44 \pm 2,98$ & $8,87 \pm 1,94$ & $9,32 \pm 3,28$ & $9,34 \pm 1,77$ & $7,30 \pm 1,68$ & $8,65 \pm 2,49$ \\
\hline C $15: 0$ & $1,00 \pm 0,38$ & $0,89 \pm 0,44$ & $0,98 \pm 0,50$ & $0,97 \pm 0,32$ & $0,98 \pm 0,14$ & $0,84 \pm 0,20$ & $1,01 \pm 0,11$ & $0,94 \pm 0,11$ \\
\hline C $16: 0$ & $23,50 \pm 2,11$ & $25,45 \pm 3,63$ & $24,34 \pm 3,40$ & $24,61 \pm 2,84$ & $25,18 \pm 2,71$ & $24,74 \pm 2,53$ & $23,51 \pm 2,95$ & $24,48 \pm 3,09$ \\
\hline C $17: 0$ & $0,60 \pm 0,50$ & $0,38 \pm 0,11$ & $0,49 \pm 0,13$ & $0,49 \pm 0,13$ & $0,97 \pm 0,24^{\mathrm{a}}$ & $0,14 \pm 0,07^{\mathrm{b}}$ & $0,36 \pm 0,11^{\mathrm{b}}$ & $0,50 \pm 0,46$ \\
\hline C 18:0 & $12,88 \pm 3,51$ & $11,98 \pm 3,88$ & $12,24 \pm 3,40$ & $12,24 \pm 3,40$ & $15,67 \pm 2,55^{\mathrm{a}}$ & $9,88 \pm 3,02^{b}$ & $11,74 \pm 2,88^{b}$ & $12,42 \pm 3,68$ \\
\hline C 20:0 & $0,13 \pm 0,05$ & $0,13 \pm 0,06$ & $0,13 \pm 0,06$ & $0,13 \pm 0,06$ & $0,11 \pm 0,09$ & $0,05 \pm 0,04$ & $0,22 \pm 0,11$ & $0,13 \pm 0,04$ \\
\hline
\end{tabular}

Nas linhas, médias seguidas da mesma letra, dentro de cada fator, não diferem $(P>0,05)$ pelo teste Tukey.

Means followed by same letter in a row, within each factor, do not differ $(P>0.05)$ by Tukey test.

Tabela 4 - Perfil de ácidos graxos insaturados e relações entre as classes em amostras de leite de cabras Saanen sob diferentes estratégias de manejo e higiene da ordenha, em três fases da lactação

Table 4 - Effects of flock management, milking sanitary conditions, and lactation stage on the milk profile of unsaturated fatty acids in Saanen goats

\begin{tabular}{|c|c|c|c|c|c|c|c|c|}
\hline \multirow[t]{2}{*}{$\begin{array}{l}\text { Ácido gra } \\
\text { Fatty acid }\end{array}$} & \multicolumn{2}{|c|}{$\begin{array}{c}\text { Manejo } \\
\text { Flock management }\end{array}$} & \multicolumn{2}{|c|}{$\begin{array}{c}\text { Ordenha } \\
\text { Milking sanitary condition }\end{array}$} & \multicolumn{3}{|c|}{$\begin{array}{c}\text { Fase de lactação (dias) } \\
\text { Lactation stage (days) }\end{array}$} & \multirow[t]{2}{*}{$\begin{array}{l}\text { Média } \\
\text { Mean }\end{array}$} \\
\hline & $\begin{array}{l}\text { Sem macho } \\
\text { Without male }\end{array}$ & $\begin{array}{l}\text { Com macho } \\
\text { With male }\end{array}$ & $\begin{array}{l}\text { Sem higiene } \\
\text { Poor hygiene }\end{array}$ & $\begin{array}{l}\text { Com higiene } \\
\text { Good hygiene }\end{array}$ & 35 & 85 & 135 & \\
\hline C $14: 1$ & $0,34 \pm 0,07$ & $0,27 \pm 0,08$ & $0,33 \pm 0,09$ & $0,28 \pm 0,06$ & $0,28 \pm 0,14$ & $0,39 \pm 0,13$ & $0,25 \pm 0,08$ & $0,30 \pm 0,05$ \\
\hline C $15: 1$ & $0,21 \pm 0,08$ & $0,23 \pm 0,09$ & $0,20 \pm 0,07$ & $0,25 \pm 0,07$ & $0,36 \pm 0,07^{\mathrm{a}}$ & $0,06 \pm 0,01^{b}$ & $0,31 \pm 0,12^{\mathrm{a}}$ & $0,22 \pm 0,05$ \\
\hline C $16: 1$ & $0,61 \pm 0,11$ & $0,59 \pm 0,14$ & $0,65 \pm 0,13$ & $0,65 \pm 0,13$ & $1,09 \pm 0,39^{\mathrm{a}}$ & $0,18 \pm 0,13^{\mathrm{b}}$ & $0,53 \pm 0,12^{\mathrm{b}}$ & $0,60 \pm 0,56$ \\
\hline C $17: 1$ & $0,30 \pm 0,10$ & $0,20 \pm 0,06$ & $0,17 \pm 0,06$ & $0,17 \pm 0,06$ & $0,45 \pm 0,26^{\mathrm{a}}$ & $0,14 \pm 0,08^{b}$ & $0,16 \pm 0,07^{b}$ & $0,25 \pm 0,041$ \\
\hline C $18: 1$ & $20,18 \pm 5,10$ & $20,83 \pm 5,19$ & $20,08 \pm 5,10$ & $20,08 \pm 5,10$ & $25,27 \pm 3,09^{\mathrm{a}}$ & $15,79 \pm 3,33^{\mathrm{c}}$ & $20,45 \pm 4,39^{b}$ & $20,51 \pm 5,59$ \\
\hline C $18: 2$ & $2,49 \pm 0,34$ & $1,31 \pm 1,08$ & $2,15 \pm 1,56$ & $2,15 \pm 1,56$ & $1,74 \pm 1,36^{\mathrm{ab}}$ & $1,28 \pm 0,29^{\mathrm{b}}$ & $2,74 \pm 1,44^{\mathrm{b}}$ & $1,90 \pm 1,39$ \\
\hline C $18: 3$ & $0,35 \pm 0,59$ & $0,88 \pm 0,18$ & $0,93 \pm 0,17$ & $0,93 \pm 0,17$ & $0,68 \pm 0,26^{\mathrm{a}}$ & $0,97 \pm 0,09^{\mathrm{b}}$ & $0,95 \pm 0,09^{\mathrm{b}}$ & $0,89 \pm 0,21$ \\
\hline SAT & $75,51 \pm 6,26$ & $76,32 \pm 6,48$ & $76,15 \pm 6,47$ & $75,68 \pm 6,49$ & $70,19 \pm 3,08^{\mathrm{c}}$ & $82,19 \pm 4,37^{\mathrm{a}}$ & $75,35 \pm 4,72^{\mathrm{b}}$ & $75,91 \pm 6,39$ \\
\hline MONO & $21,65 \pm 5,66$ & $22,14 \pm 6,23$ & $21,38 \pm 5,63$ & $22,40 \pm 6,21$ & $27,47 \pm 3,27^{\mathrm{a}}$ & $16,51 \pm 3,82^{\mathrm{c}}$ & $21,71 \pm 4,35^{\mathrm{b}}$ & $21,89 \pm 5,83$ \\
\hline POLI & $2,84 \pm 1,70^{\mathrm{a}}$ & $1,54 \pm 1,06^{\mathrm{b}}$ & $2,47 \pm 1,83$ & $1,91 \pm 1,07$ & $2,34 \pm 1,41^{\mathrm{a}}$ & $1,29 \pm 1,01^{\mathrm{b}}$ & $2,94 \pm 1,71^{\mathrm{a}}$ & $2,19 \pm 1,54$ \\
\hline $\mathrm{M} / \mathrm{S}$ & $0,29 \pm 0,09$ & $0,29 \pm 0,10$ & $0,28 \pm 0,09$ & $0,30 \pm 0,10$ & $0,39 \pm 0,06^{\mathrm{a}}$ & $0,20 \pm 0,05^{\mathrm{c}}$ & $0,29 \pm 0,07^{\mathrm{b}}$ & $0,29 \pm 0,09$ \\
\hline $\mathrm{P} / \mathrm{S}$ & $0,04 \pm 0,02^{\mathrm{a}}$ & $0,02 \pm 0,01^{b}$ & $0,03 \pm 0,02$ & $0,02 \pm 0,01$ & $0,03 \pm 0,02$ & $0,02 \pm 0,01$ & $0,04 \pm 0,02$ & $0,03 \pm 0,02$ \\
\hline $\mathrm{I} / \mathrm{S}$ & $0,33 \pm 0,10$ & $0,31 \pm 0,11$ & $0,32 \pm 0,11$ & $0,33 \pm 0,11$ & $0,42 \pm 0,06^{\mathrm{a}}$ & $0,22 \pm 0,06^{\mathrm{c}}$ & $0,33 \pm 0,08^{b}$ & $0,33 \pm 0,10$ \\
\hline AGD & $37,38 \pm 9,17$ & $36,62 \pm 9,22$ & $36,09 \pm 9,11$ & $36,92 \pm 10,11$ & $45,47 \pm 4,84^{\mathrm{a}}$ & $27,66 \pm 6,63^{\mathrm{c}}$ & $36,39 \pm 6,82^{b}$ & $36,51 \pm 9,41$ \\
\hline \multicolumn{9}{|l|}{$D F A$} \\
\hline
\end{tabular}

Nas linhas, médias seguidas da mesma letra, dentro de cada fator, não diferem $(P>0,05)$ pelo teste Tukey.

Means followed by same letter in a row, within each factor, do not differ $(P>0.05)$ by Tukey test.

$\mathrm{M} / \mathrm{S}$ - relação monoinsaturado e insaturado ( $M / S$ - monounsaturated to saturated ratio).

$\mathrm{P} / \mathrm{S}$ - relação polinsaturados e saturados ( $P / S$ - polyunsaturated to saturated ratio).

I/S - relação insaturados e saturados (I/S - Unsaturated to saturated ratio).

AGD - ácidos graxos desejáveis (insaturados + C18:0) (DFA - desirable fatty acids (unsaturated + C18:0)).

entre as fases de lactação analisadas. Nas relações entre os ácidos graxos, apenas a relação PS não diferiu $(\mathrm{P}>0,05)$. Esta relação é menor em animais ruminantes, em virtude dos processos de biohidrogenação dos ácidos graxos insaturados provenientes da dieta pelos microrganismos do rúmen (Coulon \& Priolo, 2002; Chilliard et al., 2001).
O perfil dos ácidos graxos das amostras de leite não foi influenciado pela presença do reprodutor no grupo das fêmeas nempelas condições de higiene na ordenha, o que comprova que não ocorreram reações metabólicas (lipólise) por ação microbiana. Observou-se tendência a maiores percentuais de ácidos graxos de cadeia curta e média (C4:0 a 
C12:0) aos 85 dias após o início da lactação, ocasionando conseqüentemente, decréscimo no teor de ácidos de cadeia longa, mais evidente para os ácidos esteárico (C18:0) e oléico (C18:1). Comportamento semelhante foi observado para o teor dos ácidos saturados (diferiu $(\mathrm{P}<0,01)$ conforme o período de lactação) e, conseqüentemente, dos ácidos monoinsaturados e poliinsaturados. Verificou-se também variação $(\mathrm{P}<0,05)$ nos teores de ácidos graxos desejáveis (AGD), o percentual foi menor aos 85 dias e maior aos 35 dias da lactação, estando diretamente relacionado aos teores de ácido esteárico (C18:0).

O balanço energético implica regulação de reservas corporais de energia e está associado ao aporte de ácidos graxos de cadeia longa à célula mamária. A quantidade relativa destes ácidos no produto final depende do volume secretado, regulado pelos processos de síntese/captação de ácidos graxos. No início da lactação, um desequilíbrio no balanço energético pode provocar mobilização das reservas de gordura, com conseqüente ingresso de acilgliceróis na circulação sangüínea. Maior demanda de volume de ingestão ocasiona modificações no balanço energético, com consequiência direta na síntese dos ácidos graxos (Schmidely \& Sauvant, 2001; Sanz Sampelayo et al., 2002).

Os complexos processos metabólicos de biohidrogenacão ruminal, ocasionados por possíveis variações na quantidade do volume de alimento ingerido, podem ter originado as diferenças no perfil dos ácidos graxos registradas nesta pesquisa. Os teores de determinados ácidos graxos diferiram um pouco dos valores obtidos por Fontecha et al. (2000) e Sanz Sampelayo et al. (2002), em amostras de leite de cabras Murciana Granadina, e Chornobai (1998), em amostras de leite de cabras Saanen. Variações no perfil de ácidos graxos foram observadas também por Morand-Fehr et al. (1997), Sanz Sampelayo et al. (2002) e Torii et al. (2004), ao estudarem o efeito do manejo alimentar na composição do leite de cabras.

\section{Conclusões}

A produção de leite em cabras Saanen decresce a partir do 35 o dia de lactação.

A fase de lactação influencia os teores de lipídios e a acidez do leite, de modo que os maiores valores ocorrem no final da lactação.

Os fatores manejo do rebanho e higiene da ordenha não promovem variações no perfil de ácidos graxos do leite caprino, mas o período de lactação influencia os teores de ácidos graxos saturados e insaturados.

\section{Literatura Citada}

AGANGA, A.A.; AMARTEIFIO, J.O.; NKILE, N. Effect of stage of lactation on nutrient composition of Tswana sheep and goat's milk. Journal of Composition and Analysis, v.15, n.5 p.533-543, 2002.

ANIFANTAKIS, E.M.; KADARAKIS, J.G. Contribution to the study of the composition of goat's milk. Milchwissenschaft, v.35, n.10, p.617-619, 1980.

ASSOCIATION OF OFFICIAL ANALYTICAL CHEMISTS - AOAC. Official methods of analysis. 16.ed. 4.rev. Washington: 1998. 2v. 1018p.

BARBOSA, M.; MIRANDA, R. Physico-chemical and microbiological characteristics of goat milk in Portugal. Bulletin International Dairy Federation, n.202, p.84-89, 1986.

BRASIL. Ministério da Agricultura. Secretaria Nacional da Agricultura. Instrução Normativa $\mathrm{n}^{\circ} 37$, de 8 de novembro de 2000. Regulamento Técnico de Produção, identidade e qualidade do leite de cabra. Diário Oficial da União. Disponível em: <www.Agricultura.gov.Brldasłdipoallegislacaoespecifica_leited.htm.> Acesso em: 13/05/01

CHILLIARD, Y.; FERLAY, A.; DOREAU, M. Contrôle de la qualité nutritionnele des matières grasses du lait par Iடcalimentation des vaches laitières: acides grãs trans polyinsaturès, acide linoléique conjuqué. INRA Production Animale, v.14, n.5, p.323-335, 2001.

CHORNOBAI, C.A.M. Avaliação físico-química de leite in natura de cabras cruza Saanen, ao longo do período de lactação. Maringá: Universidade Estadual de Maringá 1998, 98p. Dissertação (Mestrado em Química) - Universidade Estadual de Maringá, 1998.

CHORNOBAI, C.A.M.; DAMASCENO, J.C.; VISENTAINER, J.V. et al. Physical-chemical composition of in nature goat milk from cross Saanen throughout lactation period. Archivos Latinoamericanos de Nutrición, v.49, n.3, p.283-286, 1999.

COULON, J.B.; PRIOLO, A. La qualité sensorielle des produits laitiers et de la viande dépend des fourrages consommés par les animaux. INRA Production Animale, v. 15, p.333-342, 2002.

DELACROIX-BUCHET, A.; LAMBERET, G. Sensorial properties and typicity of goat dairy products. In: INTERNATIONAL CONFERENCE ON GOATS, 1., 2000, Tours. Proceedings.. Tours: 2000. p.559-563.

EGITO, A.S. Utilização racional do leite de cabra e seus derivados. In: REUNIÃO ANUAL DA SOCIEDADE BRASILEIRA DE ZOOTECNIA, 28., 1989, João Pessoa. Anais... João Pessoa: Sociedade Brasileira de Zootecnia, 1991. p.145p

FAOSTAT. Disponível em: <http://www.fao.org/waicent/portal/ statistics_en.asp.> Acesso em: 22/07/03.

FARIA, V.M.C.O. Estudo do rendimento e composição do leite de cabra na região Nordeste: raça Saanen. Campinas Universidade Estadual de Campinas, 1987. 95p. Dissertação (Mestrado em Tecnologia de Alimentos) - Universidade Estadual de Campinas, 1987.

FEHR, P.M.; SAUVANT, D. Composition and yield of goat milk as affected by nutritional manipulation. Journal of Dairy Science, v.63, n.10, p.1971-1880, 1980.

FOLCH, J.; LEES, M.; SLOANNE STANLEY, G.H. A simple method for isolate and purification of total lipid from animal tissues. Journal Biological Chemistry, v.226, p.497-509, 1957.

FONTECHA, J.; RIOS, J.J.; LOZADA, L. et al. Composition of goat's milk fat triglycerides analyzed by silver ion adsorption - TLC and GC - MS. International Dairy Journal, v.10, p.119-128, 2000 .

GOETSCH, A.L.; DETWEILER, G.; SALHU, T. et al. Dairy goat performance with different dietary concentrate levels in late lactation. Small Ruminant Research, v.41, p.117-125, 2001. 
GONZALO, C. Somatic cells of sheep and goat milks: analytical, sanitary, productive and technological aspects. In: INTERNATIONAL SYMPOSIUM THE FUTURE OF THE SHEEP AND GOAT DAIRY SECTORS, 2004, Zaragoza. Anais... Zaragoza: CIHEAM-IAMZ, 2004 (CD-ROM).

HAENLEIN, G.F.W. Goat milk in human nutrition. Small Ruminant Research, v.51, n.1, p.155-163, 2004.

HARTMAN, L.; LAGO, B.C.A. Rapid preparation of methyl esters from lipids. Laboratory Practice, v.22, p.475-477, 1973.

INSTITUTO ADOLFO LUTZ. Normas Analíticas do Instituto Adolfo Lutz. 3.ed. São Paulo, 1985. v.1. 533p

JAUBERT, G.; BONDIN, J.P.; JAUBERT, A. Flavour of goat farm bulk milk. In: MORAND-FEHR, P. (Ed.) Recent advances in goat research. Zaragoza: CIHEAM-IAMZ, 1997. p.89-93.

JENNESS, R. Composition and characteristics of goat milk: review 1968 - 1979. Journal of Dairy Science, v.63, n.10, p.16051630, 1980.

KARIM, G.; LOFTI, A. Studies on the milk composition of crossbreed Saanen goat. Journal Veterinary Faculty University, v.42, n.1, p.5-13, 1987.

MCCULLOUGH, F.S.W. Nutritional interest of goat's milk Present information and future prospects. In: INTERNATIONAL SYMPOSIUM THE FUTURE OF THE SHEEP AND GOAT DAIRY SECTORS, 2004, Zaragoza. Anais... Zaragoza: CIHEAM-IAMZ, 2004. (CD-ROM).

MONERET-VAUTRIN, A. Allergy to goat milk and sheep milk. In: INTERNATIONAL SYMPOSIUM THE FUTURE OF THE SHEEP AND GOAT DAIRY SECTORS, 2004, Zaragoza. Anais... Zaragoza: CIHEAM-IAMZ, 2004. (CD-ROM).

MORAND-FEHR, P.; SAMPELAYO, M.R.S.; FEDELE, Y.V. et al. Effect of roughage level and source in diets on the risk of reversing fat and protein percentages in goat milk. In: MORAND-FEHR, P. (Ed.) Recent advances in goat research . Zaragoza: CIHEAM-IAMZ, 1997. p.115-118.

MORGAN, F.; JACQUET, F.; MICAULT, S. et al. Characteristics of goat milk colleted from small and medium enterprises in Greece, Portugal and France. Small Ruminant Research, v.47, p.39-49, 2003.

NADER FILHO, A.; TRAMONTE, E.B.; AMARAL, L.A. et al. Variação das Características físico-químicas do leite de cabra durante os diferentes meses do período de lactação. Ars Veterinária, v.6, n.2, p.60-66, 1990.

PRASAD, H.; SENGAR, O.P.S. Milk yield and composition of the Barbari gota breed and its cross with Jamunapari, Beetal and Black Bengal. Small Ruminant Research, v.45, p.79-83, 2002.

PRATA, L.F.; RIBEIRO, A.C.; REZENDE, K.T. et al. Composição, perfil nitrogenado e características do leite caprino (Saanen). Região Sudeste Revista Ciência e Tecnologia de Alimentos, v.18, n.4, p.429-432, 1998.

QUEIROGA, R.C.R.E. Características físicas, químicas e condições higiênico-sanitárias do leite de cabras mestiças no Brejo paraibano. João Pessoa: Universidade Federal da Paraíba, 1995. 84p. Dissertação (Mestrado em Ciência e Tecnologia de Alimentos) - Universidade Federal da Paraíba, 1995.

ROTA, A.M.; RODRIGUEZ, P.; ROJAS, A. et al. Quantitative changes in the milk of Veratá goats during lactation. Archives Zootecnia, v.42, n.157, p.137-146, 1993.
SANZ SAMPELAYO, M.R.S.; PÉREZ, L.; ALONSO, M.J.J. et al. Effects of concentrates with different contents of protected fat rich PUFAs on the performance lactating Granadina goats. Part II. Milk production and composition. Small Ruminant Research, v.43, p.141-148, 2002.

STATISTICAL ANALYSIS SYSTEM - SAS. User's guide: statistics. Versão 6.12. Cary: North Carolina State University, 1996. 956p.

SCHMIDELY, P.; SAUVANT, D. Taux butyreux et composition de la matière grasse du lait chez les petits ruminants: effets $d$ I2 apport de matières grasses ou d2 aliment concentré. INRA Production Animale, v.14, n.5, p.337-354, 2001.

SILVA, A.M.C. Efeitos de processamento de pasteurização aplicados em leite de cabra no estado de Pernambuco. Recife: Universidade Federal de Pernambuco, 2001. 117p. Dissertação (Mestrado em Nutrição) - Universidade Federal de Pernambuco, 2001.

SIMPLÍCIO, A.A.; WANDER, A. Organização e Gestão da Unidade Produtiva na caprino-ovinocultura. In: CONGRESSO PERNAMBUCANO DE MEDICINA VETERINÁRIA SEMINÁRIO NORDESTINO DE CAPRINO-OVICULTURA, 5., 2003, Recife. Anais... Recife: Universidade Federal Rural do Pernambuco, 2003. p.177-187.

SORYAL, K.A.; ZENG, S.S.; MIN, B.R. et al. Effect of feeding treatments and lactation stages on composition and organoleptic quality of goat milk Domiati cheese. Small Ruminant Research, v.52, n.1-2, p.103-107, 2004.

SOUZA NETO, J.; GUTTIERREZ, N.A. Características gerais da caprinocultura no Estado da Paraíba. Sobral: EMBRAPA - CNPC, 1987. 23p. (Boletim de Pesquisa, 5).

SUNG, Y.Y.; WU, T.I.; WANG, P.H. Evaluation of milk quality of Alpine, Nubian, Saanen and Toggenburg breeds in Taiwan. Small Ruminant Research, v.33, p.17-23, 1999.

TORII, M.S.; DAMASCENO, J.C.; RIBEIRO, L.R. et al. physicalchemical characteristics and fatty acids composition in dairy goat milk in response to roughage diet. Brazilian Archives of Biology and Technology, v.47, n.6, p.903-909, 2004.

THOLON, P. Estudo genético quantitativo de características de importância econômica em caprinos da raça Saanen. Jaboticabal: Universidade Estadual Paulista, 2000. 54p. Monografia (Graduação em Zootecnia) - Universidade Estadual Paulista, 2000

VEINOGLOU, D.; BALTADJIEVA, M.; KALATZOTOULOS, G. et al. La composition der laite de chevre de la région de Plovidven Bulgarie et la Loannina em Gréce. Le Lait, v.62, n.613/614, p.155-165, 1982.

VOUTSINAS, L.; PAPPAS, C.; KATSIARI, M. The composition of Alpine goats milk during lactation in Greece. Journal of Dairy Research, v.57, n.1, p.45-51, 1990. 